\title{
Inhibition of return in location- and identity-based choice decision tasks
}

\author{
JAY PRATT \\ University of Toronto, Toronto, Ontario, Canada \\ ALAN KINGSTONE \\ University of Alberta, Edmonton, Alberta, Canada \\ and \\ WAYNE KHOE \\ University of California, Davis, California
}

\begin{abstract}
Three experiments were conducted to determine whether inhibition of return can be best characterized as an attentional or a motor phenomenon. In the first experiment, subjects made choice keypress responses to the location of a target (left or right) or the identity of the target ( $\mathrm{X}$ or + ) by pressing a left or right response key. In the second experiment, the display was rotated $90^{\circ}$ so that there was no direct spatial mapping between the vertically aligned stimulus display and the horizontally aligned response keys. In both experiments, inhibition of return was observed for location-based and identitybased choice responses, although more inhibition was seen in the identity-based responses. The results of the third experiment suggested that this larger inhibitory effect may be specific to the covert orienting of reflexive attention in response to the sudden appearance of a single peripheral stimulus in the identity tasks. Overall, the results are consistent with the attentional, not the motor, explanation of inhibition of return.
\end{abstract}

When an uniformative peripheral cue is brightened briefly, people are faster to detect the appearance of an object at the cued location than at an uncued or novel location (see, e.g., Posner, 1980; Rafal, Calabresi, Brennan, \& Sciolto, 1989). However, this relatively brief period of facilitation is followed by a longer period of inhibition during which people are typically slower to detect an object that appears at the cued location. Posner and Cohen (1984) termed the latter phenomenon "inhibition of return."

Inhibition of return has been found in a wide array of detection tasks. These include tasks in which the response to the appearance of the target was a simple manual keypress (e.g., Maylor, 1985; Maylor \& Hockey, 1987), a choice manual keypress (Maylor, 1985; Pratt \& Abrams, 1995), or an eye movement (Abrams \& Dobkin, 1994; Vaughan, 1984). Cued objects that change their spatial location also remain inhibited (Abrams \& Dobkin, 1994; Tipper, Driver, \& Weaver, 1991; Tipper, Weaver, Jerreat, \& Burak, 1994; but see Müller \& von Mühlenen, 1996), as

This research was supported by Natural Sciences and Engineering Research Council of Canada (NSERCC) awards 52-75095 and 5277162, as well as University of Alberta award 51-61019, to A.K. The research was also supported by Grant R29-MH45145 from the National Institutes of Health to R. A. Abrams, and we would like to thank him for the allowing us to conduct the third experiment in his laboratory. We would also like to thank Ray Klein, Elaine Fox, Steve Tipper, and especially Tram Neill for helpful comments on an earlier version of the manuscript. Correspondence should be addressed to J. Pratt, Department of Psychology, 100 St. George St., University of Toronto, Toronto, ON, Canada M5S 3G3 (e-mail: pratt@psych.utoronto.ca). do cued locations on dynamic objects (Gibson \& Egeth, 1994).

The explanation of inhibition of return has typically turned on the manner in which visual attention was oriented. For example, Posner and Cohen (1984) proposed that slower detection responses can occur at cued locations because visual attention is inhibited in returning to locations that were previously attended. Such an explanation has the advantage of being ecologically adaptive because in an attentional search, it would be more efficient to orient attention toward novel locations rather than returning attention to locations that have already been attended and no target object found (e.g., Tipper et al., 1994).

An alternative "nonattentional" account regarding inhibition of return has been put forward by Klein and Taylor (1994). They have suggested that inhibition of return reflects a response bias whereby subjects first prepare a spatial response to a cued location, and if a target object is not presented soon after the cue, the location is "tagged" and a subsequent spatial response to the cued location is inhibited. Thus, choice manual responses based on spatial location and eye movement responses will show inhibition of return. However, choice responses that do not map onto spatial locations (such as those based on color, form, or size) will not be inhibited. Additionally, Klein and Taylor assume that detection responses inherently involve some spatial localization and that because of this, simple manual responses will also show inhibition of return.

At the moment, there is evidence supporting each explanation. On the one hand, for example, Rafal et al. (1989) 
found that inhibition of return occurred with a central arrow cue only when the subjects were instructed to prepare an eye movement to the location pointed to by the arrow. If inhibition of return is an attentional effect, then slower responses should occur for targets at previously attended locations no matter how attention was oriented to the location. This did not happen in Rafal et al.; rather, inhibition of return occurred only to locations in which a motor response was prepared. Therefore, these findings support the motor explanation.

On the other hand, Reuter-Lorenz, Jha, and Rosenquist (1996) found that manipulations such as target modality and target intensity, which have previously been shown to affect attentional cuing, also affect inhibition of return. They found that lower intensity visual and auditory stimuli yield larger inhibition of return effects than do higher intensity stimuli, similar to the larger attentional cuing effects found with lower intensity stimuli. These results indicate that factors that have an impact on the attentional cuing effect also have an impact on inhibition of return, suggesting that inhibition of return is an attentional phenomenon. Thus there appears to be empirical support for both the motor and the attentional explanations.

The attentional and motor accounts do, however, yield very different predictions regarding tasks in which the response does not have a spatial component. The motor account suggests that inhibition of return will not occur in situations in which the response is based on a nonspatial characteristic of the stimuli. Conversely, the attentional account suggests that inhibition of return will happen when the target occurs at a previously attended location, regardless of what characteristic of the target the response is based on. A strong test of whether inhibition of return is motor or attentional in nature would therefore involve responses to targets based on nonspatial characteristics - that is, tasks involving a feature identification response based on the identity of a target, not the location of a target. Very few studies have examined this type of task. Rather, most studies have examined inhibition of return in detection tasks, which, as Klein and Taylor (1994) have noted, have a large spatial component.

Currently, only two studies have examined inhibition of return in feature identification tasks (also known as discrimination tasks, because the subjects must discriminate the target from a nontarget on the basis of some features). Terry, Valdes, and Neill (1994) conducted three experiments in which subjects were asked to make either detection or discrimination responses. In two basic paradigms, they employed a "target-target" procedure, in which target onset serves as the attentional cue for the next target. One paradigm involved the presentation of either a target or a nontarget to the left or right of fixation. In Experiment 1, subjects were instructed to make a simple keypress only if the target appeared (and not to respond if the nontarget appeared), and in Experiment 3 the subjects were instructed to make a choice keypress response, pressing one key for target present and one key for target absent. In the other paradigm (Experiment 2), a target and a nontarget appeared simultaneously on either side of fixation, and subjects were instructed to make a choice keypress on the basis of location of the target (left key, right key). A control task, run separately in each experiment, simply required subjects to detect the onset of a target. Terry et al. consistently found inhibition of return in the detection tasks but not in any of the three discrimination tasks-results that support the motor explanation.

There has, however, been some evidence to suggest that inhibition of return may exist in discrimination tasks. Pratt (1995) presented a peripheral cue, followed by a fixation cue, followed by either a single target (detection condition) or a target and a nontarget (discrimination condition). Unlike Terry et al.'s (1994) subjects, Pratt's subjects made eye movement responses to the location of the target stimulus. Also unlike Terry et al., Pratt found equal amounts of inhibition of return in the detection and discrimination conditions. This difference in results between the two studies was thought to have been due to the different cuing procedures used. In the target-target procedure used by Terry et al., the previously attended location always offered some information regarding a response, whereas the peripheral cue used by Pratt did not. Pratt agreed with Terry et al.'s suggestion that it may be unadaptive to inhibit returning attention to a location that has recently conveyed some useful information regarding a response.

Unfortunately, it is difficult to assess the validity of the motor explanation on the basis of the results of the choice keypress tasks used by Terry et al. (1994) and Pratt (1995). Consistent with the motor explanation, no inhibition of return was present in the discrimination tasks that did not have a spatial component (Experiments 1 and 3 of Terry et al.). Also consistent with the motor explanation, inhibition was found in one of the discrimination tasks that did involve a spatially localized response (Pratt). Inconsistent with the motor explanation, inhibition of return was not found with the location-based responses in the second experiment of Terry et al. However, because the lack of inhibition in the Terry et al. experiments may have been due to the informativeness of the previously cued location, the results of these experiments may not allow for an adequate test of the motor explanation. Additionally, the Pratt study does not represent a strong test of the motor explanation because only spatially directed discrimination responses were examined.

The present study was conducted in order to provide a more direct test of the motor explanation of inhibition of return with choice response tasks. In this study, choice manual responses were examined in two experiments. In both experiments, the choice response was based either on the location of the target or on the identity of the target. If the motor explanation is correct, inhibition of return would be expected to occur with location-based responses but not with identity-based responses. 


\section{EXPERIMENT 1}

The paradigm used in the present experiment is very similar to the one in which Pratt (1995) found inhibition of return with location-based choice responses. The major events of each trial consisted of a single peripheral cue being presented on either side of fixation, followed by a fixation cue, followed by the presentation of the target stimulus. In the location condition, a target and nontarget were simultaneously presented on each side of fixation, and the subject's response was based on the location of the target (this essentially replicates Pratt's discrimination condition). In the identity condition, a single target was presented on either side of fixation, and the subject's response was based on the identity of the target. Because eye movement responses have an inherent spatial component, manual keypress responses were used in this experiment.

The predictions related to this experiment were straightforward. The attentional explanation yields the prediction that any response will be slower if the target appears at a location that was previously attended. Thus, inhibition of return should be found in both conditions. Conversely, the motor explanation yields the prediction that inhibition of return will be found only with location-based choice responses, and that inhibition of return will thus be found in the location condition but not in the identity condition.

\section{Method}

Subjects. Eighteen undergraduate students from the University of Alberta participated in a single 1-h session. All of the subjects received course credit for their participation.

Apparatus and Procedure. The subjects were seated directly in front of a computer monitor. The distance between the subjects and the monitor was $57 \mathrm{~cm}$. A computer keyboard was placed directly in front of them so that they could easily press any of the keys.

The sequence of events on each trials is shown in Figure 1. At the start of each trial, a display consisting of a central fixation dot and two peripheral boxes (one on each side of the fixation dot) was presented for $800 \mathrm{msec}$. The peripheral boxes were $0.5^{\circ}$ on each side and $6.75^{\circ}$ from the fixation point. At the appearance of this display, subjects were instructed to fixate on the fixation dot and remain fixated throughout the trial. Following this display, a cue was presented in one of the peripheral boxes. The cue was a large dot (essentially filling the box) that appeared on the screen for $300 \mathrm{msec}$ and then was removed. After a delay of $200 \mathrm{msec}$, a cue was presented at the fixation location for $300 \mathrm{msec}$ and then removed. Following a delay of $160 \mathrm{msec}$, the target(s) were presented. In the location condition, two stimuli were simultaneously presented, an " $X$ " appeared in one box and a "+" appeared in the other box. The subjects in this condition were instructed to press the appropriate key on the keyboard as quickly as possible: If the " $\mathrm{X}$ " appeared in the left box, they were to press the " $Z$ " key; if the " $X$ " appeared in the right box, they were to press the "/" key. In the identity condition, only one stimulus was presented; either an " $X$ " or a "+" appeared in one of the boxes. Subjects in this condition were instructed to press the " $Z$ " key if the " $X$ " was presented and to press the "/" key if the "+" was presented. Pilot testing had demonstrated that subjects were able to make the discrimination without moving their eyes from the fixation location. The stimuli remained on until the subject had responded or $1,000 \mathrm{msec}$ had elapsed from the onset of the target. If the subject made an error in responding (pressed the wrong key or the reaction

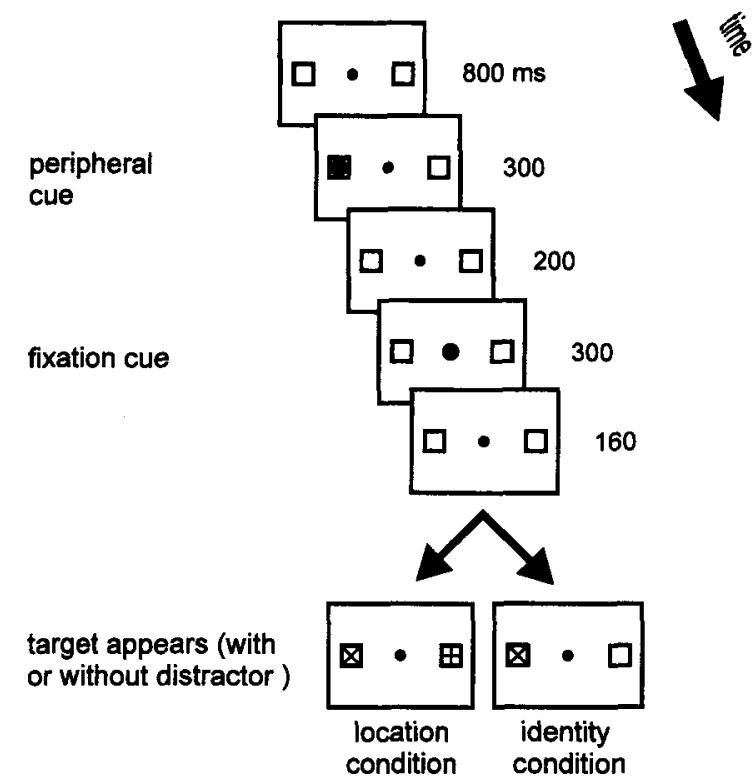

Figure 1. The timing of the trial sequence used in Experiment 1. The peripheral cue and the target could appear to the right or left of fixation. See text for details.

time [RT] was less than 100 or more than $1,000 \mathrm{msec}$ ), a brief error tone was presented. The intertrial interval was $1,500 \mathrm{msec}$.

Design. The single session consisted of two blocks of 160 trials each, one block of the location condition and one block of the identity condition. The order of conditions was counterbalanced across subjects. Within each block, the cue and target were equally likely to appear in either box, and did so randomly. Thus, half of the trials in each block involved the presentation of the target at the cued location and half at the uncued location.

\section{Results and Discussion}

The mean RTs from the correct trials are presented in Figure 2. We analyzed the mean RTs with a 2 (condition: location or identity) $\times 2$ (trial type: cued or uncued) analysis of variance (ANOVA). There was a reliable effect of condition $\left[F(1,17)=163, M S_{\mathrm{e}}=657, p<.0001\right]$, with RTs in the location condition $(407 \mathrm{msec})$ faster than in the identity condition ( $485 \mathrm{msec}$ ), suggesting that the identity decision was more difficult than the location decision. There was also a reliable effect of trial type $\left[F(1,17)=13.4, M S_{\mathrm{e}}=347, p<.005\right]$, with cued locations (454 msec) having longer RTs than uncued locations $(437 \mathrm{msec})$. This is the typical inhibition of return effect. Importantly, the condition $\times$ trial type interaction was also reliable $\left[F(1,17)=5.9, M S_{\mathrm{e}}=205, p<.03\right]$, with more inhibition observed in the identity condition $(24.2 \mathrm{msec})$ than in the location condition $(7.8 \mathrm{msec})$. Post hoc $t$ tests confirmed that inhibition occurred in both the location condition $[t(17)=2.1, p<.05]$ and the identity condition $[t(17)=3.5, p<.005]$. The finding of inhibition in the location condition replicates Pratt's (1995) finding.

The presence of inhibition in the identity condition is inconsistent with the predictions of the motor explanation. The possibility existed, however, that location-based pro- 


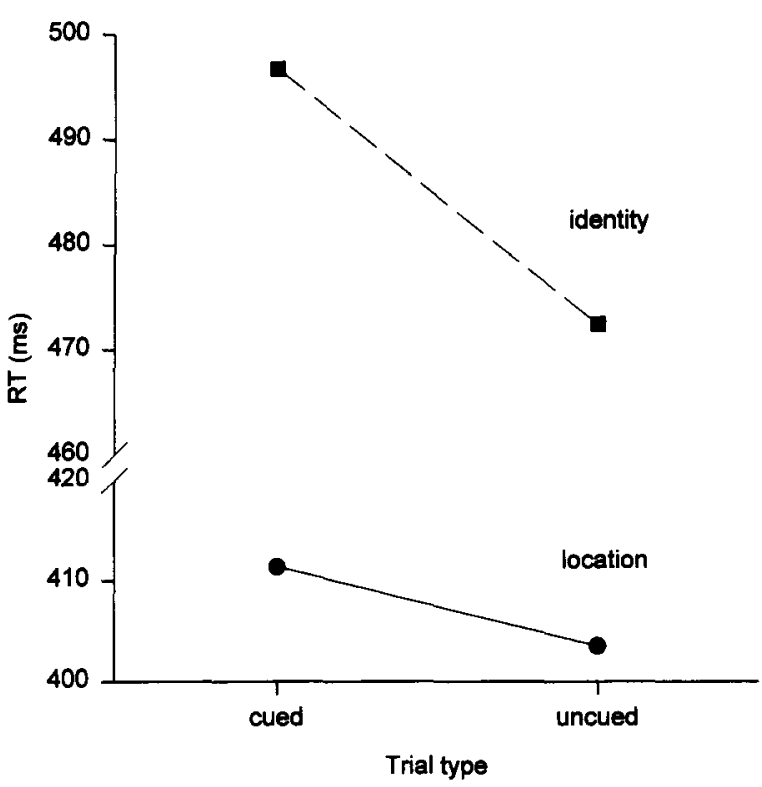

Figure 2. Mean reaction times (RTs) for the correct trials in the identity and location conditions in Experiment 1.

cesses were exerting some influence in the identity condition. This was because on half of the trials, the target stimulus appeared on the same side as the correct response key (either an "X" at the left location or a "+" at the right location), whereas on the other half of the trials the target stimulus appeared on the opposite side of the response (either an "X" at the right location or a " + " at the left location). It may have been that the inhibition of return from the identity condition occurred only when the target and response were on the same side of fixation (i.e., the response was spatially mapped to the location and the identity of the stimulus). To examine this possibility, the data from the identity condition were reanalyzed with a 2 (trial type: cued or uncued) $\times 2$ (stimulus-response compatibility: same or opposite) ANOVA. Because of problems with two data files, data from 16 subjects were used in this analysis. Overall, cued trials $(496 \mathrm{msec})$ were slower than uncued trials $(473 \mathrm{msec})$ $\left[F(1,15)=9.1, M S_{\mathrm{e}}=926, p<.01\right]$, and same trials (474 msec) were faster than different trials $(496 \mathrm{msec})$ $\left[F(15)=7.6, M S_{\mathrm{e}}=903, p<.05\right]$. Inconsistent with the spatial mapping notion, the inhibitory effect was smaller in same trials $(18 \mathrm{msec})$ than in different trials $(27 \mathrm{msec})$, although the interaction was not significant $[F(15)<1.6$, $\left.M S_{\mathrm{e}}=189, p>.22\right]$. Thus, spatial mapping does not affect inhibition of return in the identity condition.

In order to determine whether the order of the conditions affected the inhibition, a 2 (order: location then identity or identity then location) $\times 2$ (condition) $\times 2$ (trial type) ANOVA was performed. The three-way interaction was not significant $\left[F(1,16)<1, M S_{\mathrm{e}}=218\right]$, indicating that no order effects were present in the experiment.

In addition to RTs, the percentage of correct responses was examined. These data are shown in Table 1 and were analyzed with the same $2 \times 2$ ANOVA originally used on the mean RTs. A reliable effect occurred for condition $\left[F(1,17)=5.9, M S_{\mathrm{e}}=165, p<.03\right]$, with fewer correct responses in the identity condition. No effect of trial type was found $\left[F(1,17)<2.0, M S_{\mathrm{e}}=4.5, p>.15\right]$, nor was there an interaction $\left[F(1,17)<1, M S_{\mathrm{e}}=3.9\right]$. The error rates were consistent with those found by Pratt (1995).

The main finding from the present experiment was that inhibition of return was present in both location-based and identity-based choice response tasks. In fact, more inhibition of return was found in the identity-based task than in the location-based task. Further, the inhibition in the identity condition was present regardless of the spatial mapping between the stimulus and the response. Taken together, the results are inconsistent with the motor explanation for inhibition of return. However, three quarters of the total trials used in the experiment were those in which the location of the target stimulus was the same as the location of the response key (i.e., left target-left response, right target-right response). This high level of spatial compatibility throughout the experiment may have allowed some location-based processes to remain active, biasing the experiment in favor of finding inhibition of return. In order to examine choice decision responses in situations in which the stimulus and response were always much less compatible, the second experiment was conducted.

\section{EXPERIMENT 2}

Experiment 2 was conducted to replicate and extend the findings of Experiment 1. The procedure in Experiment 1 was replicated exactly, except that the monitor was rotated $90^{\circ}$ so that the display was aligned vertically instead of horizontally. We reasoned that this situation would provide a stronger test of the motor explanation by reducing the location-based stimulus-response compatibility inherent in the identity condition of Experiment 1 . Thus, in the present experiment, subjects would have to determine the identity of the target with a response that was arbitrary with respect to the location of the stimulus.

The predictions in Experiment 2 remained the same as those in the first experiment. If the motor explanation is correct, inhibition of return should be present in the location condition but not in the identity condition.

Table 1

Error Rate (in Percent) From Experiments 1, 2, and 3

\begin{tabular}{clcc}
\hline Experiment & \multicolumn{1}{c}{ Trial Type } & Location & Identity \\
\hline 1 & Cued & 5.5 & 16.8 \\
& Uncued & 4.4 & 15.8 \\
2 & Cued & 7.0 & 13.6 \\
& Uncued & 6.6 & 9.1 \\
3 & Cued (keypress error) & 5.6 & 12.8 \\
& Uncued (keypress error) & 6.6 & 10.6 \\
& Cued (eye movement) & 11.0 & 7.8 \\
& Uncued (eye movement) & 8.7 & 7.5 \\
\hline
\end{tabular}




\section{Method}

Subjects. Eighteen undergraduate students from the University of Alberta participated in a single 1-h session. All of the subjects received course credit for their participation.

Apparatus and Procedure. The apparatus and procedure were exactly the same as those used in Experiment 1 except for one important difference. In Experiment 2, the monitor was rotated clockwise $90^{\circ}$. This served to place the peripheral boxes above and below the fixation point rather than to the left and right. In the location condition, subjects were instructed to press the " $Z$ " key if the target was above the fixation and the "/" key if the target was below the fixation. The instructions in the identity condition were the same as those in Experiment 1.

Design. The single session consisted of two blocks of 160 trials each, one block of the location condition and one block of the identity condition. The order of conditions was counterbalanced across subjects. Within each block, the cue and target were equally likely to appear in either box, and did so randomly. Thus, half of the trials in each block involved the presentation of the target at the cued location and half at the uncued location.

\section{Results and Discussion}

The mean RTs from the correct trials are presented in Figure 3 . We analyzed the mean RTs with a 2 (condition: location or identity) $\times 2$ (trial type: cued or uncued) ANOVA. There was a reliable effect of condition $[F(1,17)$ $\left.=8.7, M S_{\mathrm{e}}=2,250, p<.01\right]$, with RTs in the location condition $(482 \mathrm{msec})$ faster than those in the identity condition ( $515 \mathrm{msec})$, suggesting, as before, that the identity decision was more difficult than the location decision. There was also a reliable effect of trial type $\left[F(1,17)=17.5, M S_{\mathrm{e}}=531, p<.001\right]$, with cued locations $(510 \mathrm{msec})$ having longer RTs than uncued locations $(487 \mathrm{msec})$. Thus, the inhibition of return effect was observed in both Experiments 1 and 2. The condition $\times$ trial type interaction was also reliable $[F(1,17)=$ $\left.12.0, M S_{\mathrm{e}}=259, p<.005\right]$, with more inhibition in the

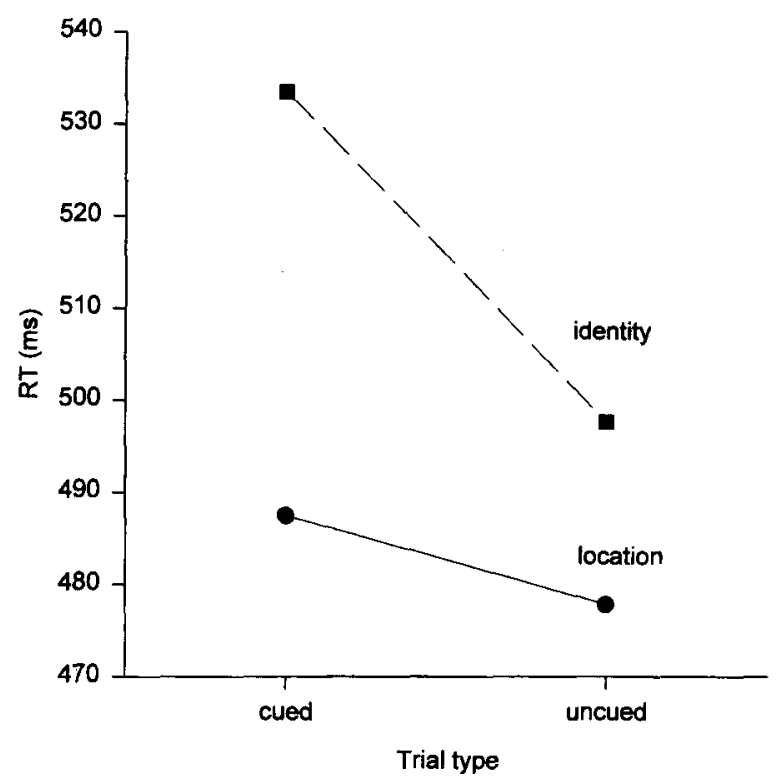

Figure 3. Mean reaction times (RTs) for the correct trials in the identity and location conditions in Experiment 2. identity condition ( $35.9 \mathrm{msec}$ ) than in the location condition $(9.6 \mathrm{msec})$. Post hoc $t$ tests confirmed that inhibition occurred in both the identity $[t(17)=4.3, p<.001]$ and the location $[t(17)=2.3, p<.05]$ conditions.

Although the stimuli and responses did not share the same strong spatial mapping as they did in Experiment 1, subjects in the present experiment may have mapped the above and below stimulus locations to the left and right keypress responses. To examine for any stimulusresponse compatibility effects, the data from the identity condition were analyzed with a 2 (trial type: cued or uncued) $\times 2$ (stimulus-response compatibility: same or opposite) ANOVA. Overall, cued trials $(534 \mathrm{msec})$ were slower than uncued trials $(499 \mathrm{msec})[F(1,17)=19.6$, $\left.M S_{\mathrm{e}}=1,152, p<.001\right]$, and same trials ( $\left.507 \mathrm{msec}\right)$ were faster than different trials $(526 \mathrm{msec})\left[F(17)=6.7, M S_{\mathrm{e}}=\right.$ $973, p<.05]$. Inconsistent with any mapping effects, the inhibitory effect was smaller in same trials $(29 \mathrm{msec})$ than in different trials $(41 \mathrm{msec})$, although the interaction was not significant $\left[F(17)<2.0, M S_{\mathrm{e}}=511, p>.19\right]$, indicating that the spatial mapping did not affect inhibition of return in the identity condition.

In order to determine whether the order of the conditions affected the inhibition, a 2 (order) $\times 2$ (condition) $\times 2$ (trial type) ANOVA was performed. Once again, the three-way interaction was not significant $[F(1,16)<1$, $M S_{\mathrm{e}}=53$ ], indicating that no order effects were present in the experiment.

The percentage of correct responses is also shown in Table 1 . These data were analyzed with the same $2 \times 2$ ANOVA first used on the RT data, and marginally reliable effects were found for condition $\left[F(1,17)=4.1, M S_{\mathrm{e}}=\right.$ $58, p<.06]$ and for trial type $\left[F(17)=3.9, M S_{\mathrm{e}}=18, p<\right.$ $.07]$, with a trend for fewer correct responses in the identity condition and in cued location trials. The interaction was significant $\left[F(17)=5.3, M S_{\mathrm{e}}=9.4, p<.05\right]$, with the most errors occurring on the cued trials in the identity condition. It is important to note that this interaction indicates that a speed-accuracy tradeoff was not present in this experiment, because the cued trials in the identity condition also yielded the longest response latencies.

Overall, the results from Experiment 2 replicated the results from Experiment 1. Inhibition of return was found in both the location and identity conditions, with more inhibition in the identity condition. Importantly, the inhibition found in the identity condition occurred despite the fact that the stimulus-response mapping in the identity condition was completely arbitrary. Thus, there was evidence that inhibition of return was present even in a choice response task in which there should have been little or no involvement from location-based response processes.

\section{EXPERIMENT 3}

In the first two experiments, much larger inhibition of return effects were found in the identity conditions than in the location conditions. This may have been due to the fact that in the identity conditions a single stimulus ap- 
peared in one visual hemifield whereas in the location conditions, stimuli appeared in both hemifields. Thus, in the identity conditions, the location of the target was indicated by the abrupt onset of a single stimulus. Such an abrupt onset would summon a reflexive shift of covert attention to the target location (see, e.g., Yantis, 1993). It is our hypothesis that inhibition of return may be especially tuned to this form of orienting. Hence, the inhibition of return effects were larger in the identity conditions than in the location conditions when attention was unlikely to be oriented to a unique location.

The present experiment was conducted to examine the possibility that the larger inhibition of return effects in the identity conditions of Experiments 1 and 2 were due to attention being oriented toward the location of the stimulus onset. In the identity condition of this experiment, a target appeared in one of the two peripheral locations and subjects had to determine whether the target was an "X" or a "+". Additionally, a distractor stimulus (a small square) was presented in the opposite peripheral location. Thus, attention should not be drawn to only the target location because of the simultaneous onset of the distractor. If the larger inhibition of return effects in the previous identity conditions were specific to the effect of reflexive covert orienting of attention to an isolated target onset, then the inhibition of return effects in this experiment should be about the same for both identity and location conditions because in both conditions the onset of a target in one hemifield coincided with the onset of a distractor stimulus in the other hemifield. Also, to ensure that the inhibition of return found in the previous experiments was not due to the overt orienting of attention, the subjects' eye position was monitored.

\section{Method}

Subjects. Ten undergraduate students from Washington University participated in a single $1-\mathrm{h}$ session. All of the subjects received $\$ 5$ for their participation.

Apparatus and Procedure. The apparatus and procedure were exactly the same as those used in Experiment 1 except for three important differences. First, in the identity condition, a distractor (a small square) was presented in the peripheral location opposite that of the target. The subjects were instructed that on trials in the identity condition a square would appear in one location and in the other location an "X" or a "+" would appear, and that they should ignore the square and determine the identity of the target. The second difference was that eye position was monitored throughout the experiment with a scleral-reflectance eye movement monitor (ASL Model 210). A trial was recorded as an error and not used in the analysis if an eye movement of more than $1^{\circ}$ from the fixation point occurred. These trials were not replaced in the experiment. The third difference was that the " $Y$ " and "B" keys on the keyboard were used as response keys ("Y" key for the left hand, " $B$ " key for the right hand). In the location condition, subjects pressed the "Y" key if the target was in the left location and the " $B$ " key if the target was in the right location. In the identity condition, subjects pressed the "Y" key if the target was an " $X$ " and the " $B$ " key if the target was a "+".

Design. The single session consisted of two blocks of 120 trials each, one block of the location condition and one block of the identity condition. The order of conditions was counterbalanced across subjects. Within each block, the cue and target were equally likely to appear in either box, and did so randomly. Thus, half of the tri- als in each block involved the presentation of the target at the cued location and half at the uncued location.

\section{Results and Discussion}

The mean RTs from the correct trials are presented in Figure 4. We analyzed the mean RTs with a 2 (condition: location or identity) $\times 2$ (trial type: cued or uncued) ANOVA. There was a reliable effect of condition $[F(1,9)$ $\left.=59, M S_{\mathrm{e}}=1,027, p<.0001\right]$, with RTs in the location condition ( $505 \mathrm{msec})$ faster than those in the identity condition $(583 \mathrm{msec})$. There was also a reliable effect of trial type $\left[F(1,9)=11.9, M S_{\mathrm{e}}=125, p<.01\right]$, with cued locations $(550 \mathrm{msec})$ having longer RTs than uncued locations $(538 \mathrm{msec})$. Unlike the previous two experiments, the condition $\times$ trial type interaction was not reliable $\left[F(1,9)<1, M S_{\mathrm{e}}=147\right]$.

In order to determine whether the order of the conditions affected the inhibition, a 2 (order) $\times 2$ (condition) $\times 2$ (trial type) ANOVA was performed. As in the previous two experiments, the three-way interaction was not significant $\left[F(1,16)<1, M S_{\mathrm{e}}=157\right]$, indicating that no order effects were present.

The percentage of correct responses is also shown in Table 1 . These data were analyzed with a 2 (error type: keypress or eye movement) $\times 2$ (condition) $\times 2$ (trial type) ANOVA. The only significant finding was the task $X$ error type interaction $\left[F(1,9)=12.4, M S_{\mathrm{e}}=24.8, p<\right.$ $.01]$, indicating that fewer errors were made with keypress responses in the location conditions than with any other responses in any other condition.

The finding of approximately equal inhibition of return effects for the location ( $10.9 \mathrm{msec})$ and the identity $(13.6 \mathrm{msec})$ conditions in the present experiment suggests that the larger effects found in the identity condi-

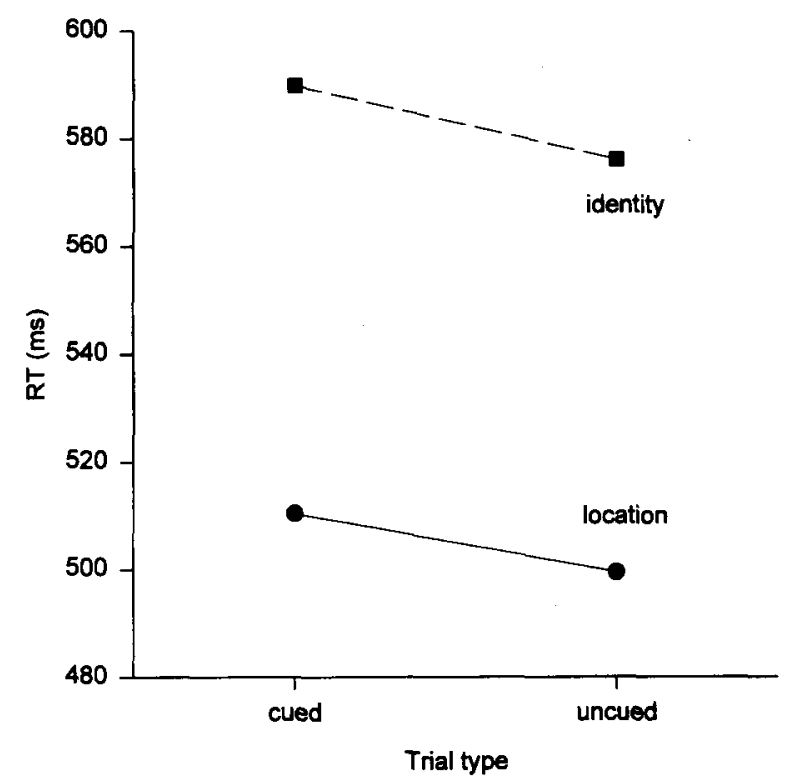

Figure 4. Mean reaction times (RTs) for the correct trials in the identity and location conditions in Experiment 3. 
tions of the previous two experiments were due to attention being covertly oriented to the location of the abrupt onset of the target stimulus. Moreover, the results also indicate that the inhibition of return found in the location and identity conditions of the previous experiments were not due to eye movements. Finally, as in Experiment 2, inhibition of return was found despite the fact that the spatial orientation of the response keys did not directly correspond to the orientation of the stimuli.

\section{GENERAL DISCUSSION}

The present study was conducted to test some of the tenets of the motor explanation of inhibition of return. The motor explanation, as defined by Klein and Taylor (1994), suggests that inhibition of return is a bias against responding to an event that occurs at a location to which a response has previously been prepared. This is an alternative to the traditional attentional explanation of inhibition of return, which suggests that attention resists returning to a location that has previously been attended.

In their formulation of the motor explanation, Klein and Taylor (1994) have suggested that inhibition of return should occur only when a response is spatially directed. Thus, inhibition of return should occur with simple detection responses as well as choice responses that involve spatial localization, but should not occur with responses based on nonspatial attributes. In the first two experiments, we examined choice manual keypress responses based on either the location of the target (where the motor explanation would predict inhibition of return) or on the identity of the target (where the motor explanation would not predict inhibition of return).

Importantly, we found inhibition of return regardless of whether or not the response was location or identity based. This result occurred when the location of the stimulus shared the same spatial mapping as the response (Experiment 1) and when the mapping between the stimuli and responses was orthogonal (Experiments 2 and 3 ). The finding of robust inhibition of return effects with choice response tasks based on the identity of the stimuli is strongly inconsistent with the motor explanation.

The present results are consistent with the attentional explanation of inhibition of return. Recall that the attentional explanation suggests that attention is biased against returning to a previously attended location, thus increasing response latencies for all types of responses to targets that have appeared at previously attended locations. In the present study, a single cue suddenly appearing and then disappearing in the periphery presumably captured attention at that location (Yantis, 1993). Subsequently, choice decision responses were slower whenever the target appeared in the same location as the previously presented cue, regardless of whether the response was based on the location of the target or the identity of the target. Such findings are consistent with the notion that attention is inhibited in returning to the previously attended location.

The finding that larger inhibition of return effects occurred in the identity conditions of Experiments 1 and 2, in which a single peripheral target was presented, and did not occur in Experiment 3, in which a target and a distractor were presented, suggests that inhibition of return may be greater for reflexive shifts of attention to abrupt stimulus onsets. Presumably, the appearance of the cue produces a reflexive orienting of attention to that location. Attention is then subsequently inhibited to return to that location. In the identity conditions of Experiments 1 and 2, the appearance of the single peripheral target should have also produced a reflexive orienting of attention, and this orienting of attention would have been inhibited if the target appeared at the cued location. In the location conditions of Experiments 1 and 2, target onset coincided with the onset of a distractor stimulus, suggesting that orienting to the target may have been more volitional than reflexive. Thus, it seems possible that the larger inhibition of return effects found in the identity conditions as compared with those found in the location conditions of the first two experiments reflects that fact that inhibition of return is greater for reflexive orienting than for volitional orienting.

Taken together, the results from the present study suggest that there may be a difference between the inhibition found in the reflexive orienting of attention to a location and the more controlled orienting of attention to a location. Thus, the Klein and Taylor (1994) proposal that responses based on a spatial dimension are substantially different from responses based on nonspatial dimensions may not be correct. Rather, with regard to inhibition of return, the salient difference may be best characterized as a difference between reflexive and controlled orienting toward a spatial location.

In conclusion, the present form of the motor explanation cannot account for the inhibition of return effects found for the identity-based responses in the present study. Rather, the present results are consistent with the attentional explanation of inhibition of return, which suggests that responses will be slower for targets presented at previously attended locations.

\section{REFERENCES}

ABRAMS, R. A., \& DoBkIN, R. S. (1994). Inhibition of return: Effects of attentional cuing on eye movement latencies. Journal of Experimental Psychology: Human Perception \& Performance, 20, 467-477.

GiBsON, B. S., \& EGETH, H. (1994). Inhibition of return to object-based and environment-based locations. Perception \& Psychophysics, 55, 323-339.

KLEIN, R., \& TAYLOR, T. L. (1994). Categories of cognitive inhibition with reference to attention. In D. Dagenbach \& T. Carr (Eds.), Inhibitory processes in attention, memory, and language (pp. 113-150). New York: Academic Press.

MAYLOR, E. A. (1985). Facilitatory and inhibitory components of orienting in visual space. In M. I. Posner \& O. S. M. Marin (Eds.), Attention and performance $X I$ (pp. 189-204). Hillsdale, NJ: Erlbaum.

MAYLOR, E. A., \& HoCKEY, R. (1987). Effects of repetition on the facilitatory and inhibitory components of orienting in visual space. Neuropsychologia, 25, 41-54.

Müller, H. J., \& vON MüHLENEN, A. (1996). Attentional tracking and inhibition of return in dynamic displays. Perception \& Psychophysics, 58, 224-249.

PoSNER, M. I. (1980). Orienting of attention. Quarterly Journal of Experimental Psychology, 32, 3-25. 
PosNer, M. I., \& CoHEN, Y. (1984). Components of visual orienting. In H. Bouma \& D. G. Bouwhuis (Eds.), Attention and performance $X$ (pp. 531-556). Hillsdale, NJ: Erlbaum.

PRATT, J. (1995). Inhibition of return in a discrimination task. Psychonomic Bulletin \& Review, 2, 117-120.

PRATT, J., \& ABRAMS, R. A. (1995). Inhibition of return to successively cued spatial locations. Journal of Experimental Psychology: Human Perception \& Performance, 21, 1343-1353.

Rafal, R. D., Calabresi, P. A., Brennan, C. W., \& Sciolto, T. K. (1989). Saccade preparation inhibits reorienting to recently attended locations. Journal of Experimental Psychology: Human Perception \& Performance, 15, 673-685.

Reuter-LoRenz, P. A., JhA, A. P., \& Rosenquist, J. N. (1996). What is inhibited in inhibition of return? Journal of Experimental Psychology: Human Perception \& Performance, 22, 367-378.

Terry, K. M., Valdes, L. A., \& NeILl, W. T. (1994). Does "inhibition of return" occur in discrimination tasks? Perception \& Psychophysics, 55, 279-286.
TIPPER, S. P., Driver, J., \& WeAVER, B. (1991). Object-centered inhibition of return of visual attention. Quarterly Journal of Experimental Psychology, 43A, 289-298.

TiPPER, S. P., WeaVer, B., JerReat, L. M., \& Burak, A. L. (1994). Objectand environment-based inhibition of return of visual attention. Journal of Experimental Psychology: Human Perception \& Performance, 20, 478-499.

VAUGHAN, J. (1984). Saccades directed at previously attended locations in space. In A. G. Gale \& F. Johnson (Eds.), Theoretical and applied aspects of eye movement research (pp. 143-150). Amsterdam: NorthHolland.

YANTIS, S. (1993). Stimulus-driven attentional capture. Current Directions in Psychological Science, 2, 156-161.

(Manuscript received May 28, 1996; revision accepted for publication September 30, 1996.) 